\title{
Students' perceptions of a selected aspect of a computer mediated academic writing program: An activity theory analysis
}

\author{
John Brine \\ The University of Aizu

\section{Margaret Franken \\ University of Waikato}

The use of activity theory is considered in the evaluation of a web based academic writing course in a New Zealand university. Activity theory is an aspect of sociocultural theory and provides a model for the understanding of goal directed social activity. Like other recent developments in applied linguistics, research and evaluation in second language writing has been influenced by sociocultural theory, because it emphasises the social, rather than the individual, context of writing. The primary purpose in carrying out this study was to illuminate the use of activity theory as a formative evaluation technique for the improvement of large academic writing courses supported through the web conferencing features of a course management system, Web Crossing. Data were in the form of international student responses to prompts made in online diaries on a weekly basis throughout the course. An activity theory orientation guided the design of the prompts and the analysis of the data. Activity analysis allowed the researchers to appreciate the tensions and difficulties for students in managing the group processes that the web mediated instruction afforded or constrained. The study also suggests that the set of guiding questions derived from Jonassen and Rohrer-Murphy (1999) may be useful for future evaluations and research.

\section{Introduction}

This paper reports on a study that sought to capture and analyse the perceptions of the 120 international students enrolled in a first semester, first year, web based academic writing course in a New Zealand university 
in 2003. All students had met the university IELTS $^{1}$ requirement for undergraduate students of 5.5. This particular paper however reports only on a selection of observations from the cohort. Like many other tertiary institutions in New Zealand at that time, this university was attempting to address the need to provide courses for the then increasing numbers of international students, that both reflected theoretical and research advances in academic writing for second language learners, and provided such intervention in an effective way.

Web based practices as part of the instructional design are perceived as a way to achieve these dual goals. Therefore, they have become an important focus for pedagogical investigation. In this paper, we report on two aspects of the web based programs that were likely to be unfamiliar to many of the students: the co-construction of text and peer evaluation. Data concerning students' perspectives was generated in the context of, and through the medium of the web based writing program.

One purpose of this paper is to report on how the insights gained from an activity analysis can positively affect changes in the operation of a computer mediated writing program. This purpose is carried out through a description of students' responses in the section below on observations of the data. Another quite different purpose is to present the trialing of activity theory as an interpretative framework used for data generation and analysis. The activity theory framework has been applied by a number of researchers, but has been restricted largely to ethnographic data (see for instance Prior 1998; Russell 1997). The data in the present study is restricted to the duration of the course and is in the form of students' reflections posted in individual private web conference areas. Furthermore, the purpose of the research was not to demonstrate a link between web conferences, or discussion forums, and second language academic writing, but to develop an evaluation procedure for iteratively improving the use of such systems, which are already widely in use.

\section{An activity theoretic orientation}

The researchers in this study were guided by an activity theoretic orientation to incorporating student perspectives. Activity theory proposes that the unit of analysis, the primary observational and activity unit, consists of the contextualised setting in which human activity takes place. Activity theory is consistent with, and can be seen as a tool of, recent socio-

\footnotetext{
${ }^{1}$ IELTS means International English Language Testing System, which establishes language proficiency standards used as benchmarks for entry into universities in English speaking countries worldwide.
} 
cultural or "ecological" approaches to research in second language learning (Blin, 2004; Belz, 2002; Lantolf, 2000; Thorne \& Payne, 2005; Van Lier, 2000). Socio-cultural approaches to understanding second language writing provide an important redirection of attention away from individual cognition that has been the main focus of past research in this area. Sociocultural approaches to research seek to illuminate interactions among participants and with the learning context. They allow us to see how thinking is "distributed" and shared among participants in the activity, because as Pea (1993) states, "the mind rarely works alone" (p. 47). The appropriateness of using an activity theoretic framework for the study of web mediated activity is captured by Hutchby's (2001) claim that it allows us to focus on people interacting "through, around and with technology" (p. 450).

An activity system includes six main features: subjects (the participants in the activity), mediating artefacts, objects (the outcomes of the activity), rules, community, and divisions of labour (Cole \& Engestrom 1993; Kaptelinin, Nardi \& MacCauley 1999; Jonassen \& Rohrer-Murphy 1999; Lewis 1997).

Activity theory is concerned with human social activity, rather than individual activity, as a fundamental unit of analysis in research. Within activity systems, subjects are involved in work directed toward objects in order to attain an intended outcome. In carrying out actions by working on objects, the subject makes use of internal or external artefacts. For example, in order to complete a piece of written work (object), a student (subject) may make use of a word processing application (external artefact) while also considering a particular structure and genre of writing (internal artefact) learned previously. In our course, there were several related writing activities, all directed toward different specific objects (different assignments). However, the intended outcomes, which motivated the activities, were the completion of the overall course and the corresponding learning.

The external artefact (word processor, or plan for writing) mediates between the subject and the object, and both affords and constrains the completion of the activity. For example, the word processor has been designed with features and characteristics that can support, or afford, the completion of writing (object). However, at the same time, the word processor can constrain writing, for example, by simplifying and possibly encouraging superficial aspects of document change, or enable conditions that may detract from getting the task completed.

Engestrom (1991) developed an extended social model of an activity, which adds a community component, comprised of those who share the same 
object. Added to this extended model are rules that mediate between subject and community, and the division of labour (or roles) to mediate between object and community. In this extended model, activity is carried out within a community. Since second language writing and computer assisted language learning are socio-cultural contexts rather than merely coincidental collections of individual learners, activity theory is used to elucidate the social practices involved in a specific community of learners.

Within the activity framework, linguistic tools play a crucial role in accomplishing the goals of the activity. As Leont'ev (1981) states, in mediating activity, tools "[connect] humans not only with the world of objects, but with other people" (p. 56). Within the activity of co-constructed second language writing, computers, and the web based practices they enable, are the mediating artefacts, or tools.

Jonassen and Rohrer-Murphy (1999) discuss in detail the types of questions one may ask of participants from an activity theoretic stance. The questions used in the present research were organised within the salient categories of an activity system. The structure of the activity system provided a framework to analyse the goal directed behaviour of the student groups. Appendix 1 contains a modified list of these questions. This list provided the framework for the questions we asked of the students in the present study, in an attempt to understand their perspectives on the course. These questions acted as prompts which students were required to respond to on a weekly basis.

\section{The setting and participants}

The academic writing and research skills course, which provided the setting for the present study, consisted of two 2-hour classes per week for 12 weeks in the first semester of the academic year. The course covered aspects of academic writing, but in addition to this, student tasks required participation in web based conferencing, co-construction of text, and other activities such as computer mediated peer evaluation. It is the coconstruction of text which is the activity reported upon in this paper.

Web Crossing (http://www.webcrossing.com/), known within Waikato University as Class Forum, is the Internet software that was used as the vehicle for web mediated activity. Class Forum permits students to interact in a class and group discussion area, and to post group texts and group comments, as well as make individual private postings in personal folders.

The latter provided the context for weekly diary entries which required students to give their viewpoints on features of the course by means of weekly diary entries posted to Class Forum (See Appendix 2 for the diary 
entry prompts that relate to web based aspects of the course, and coconstruction.) Appendix 2 also includes a description of the task requirements for the course aligned to the time when the responses to diary entry prompts were to be posted.

While the diary entry prompts were written for students to reflect on aspects of the course at the time, they were referenced also to the categories and questions from Jonassen and Rohrer Murphy (1999) as listed in Appendix 1.

The students in the course were mainly, but not exclusively, from China. However, all shared the fact that they were entering the New Zealand university experience for the first time. As such, they were not expected to have had much experience with co-construction of text, nor to have had that experience in a computer mediated format.

\section{Method}

\section{Data collection and analysis}

The data in the present study consisted of the individual reflective diary entries that students posted on the web for only their teachers to see. Private diary entries, in the same web medium we were researching, were a non-intrusive way of collecting reflective data. Though, in comparison to other forms of collecting reflective data, the posted reflections were further removed from activity than would be, for example, situated protocols (Smagorinsky, 1997). Furthermore, the diary entries could be seen to have ecological validity in that the teacher engaged in a process of feedback on issues raised in the diaries, sometimes on a one to one basis and at other times with the whole class in the shared discussion area.

The data were generated in the context of course requirements and activities. However, consent was gained from students to use these sources of data for research purposes.

As a situated study of writing, this study also sought additional data in the form of teacher reflection. However, as this is not within the scope of the present paper, the teacher self-report data is not considered here. A study of greater scope would seek to employ additional methods of data collection such as interviews with the teacher and selected students, classroom observations, and a more extensive collection of writing samples.

The data were analysed by the two researchers and the class teacher. Team discussions were held to gather initial insights regarding the general 
themes found in the data and the development of possible coding categories. The coding categories were based on the components of the activity theory model: subject, mediating artefact, object, rules, community, and division of labour (See Appendix 1). These categories represented starting points for the analysis and interpretation of data. The coding categories were then applied on a sample of the reflective diaries with refinement of categories. This can be seen as a "consensus process" (Smagorinsky, 1997) of data analysis, sorting, and interpretation.

Having categorised the data, a further interpretive perspective was applied, that of affordances and constraints. Affordances, a concept developed by Gibson (1979), allows us to view activity, and the technology that mediates activity, in terms of the potential and the limitations that are presented to learners. In this sense, technology is not responsible for learning or change. Rather, as van Lier (2000) states, "An affordance is a property of neither the actor nor of an object: it is the relationship between the two" (p. 252). It is in this sense that the activity system, the interaction of technology, learner, and object enables learning and change. Lincoln and Guba (1985) have expressed a similar idea as "mutual simultaneous shaping."

Educational technologies have often been considered to be independent variables which when varied have causal effects on learning outcomes. The interpretive perspective of affordance is useful to counteract preconceptions of how the technology nested within an activity may or may not "cause" learning in students. Inclusion of student perspectives allows us to better interpret how a technology may or may not work for students in ways not necessarily anticipated by the teacher. While the term affordances focuses on what technology enables students to do, what is also evident is the fact that at times students were not able to complete certain activities successfully due to constraints (Brine, Johnson, Franken \& Campbell, 2002).

\section{Observations of the data}

\section{The activity of co-construction}

Students were initially assigned to work in groups of about 9 or 10 members. These were later reduced to four or five members. The activities reported on in this paper for these two group arrangements were to coconstruct an introduction for an essay, and later a full 1,000 word essay. Many academic writing courses in New Zealand universities, particularly in the area of business writing, expect students to work in groups not only to generate ideas and plans for writing but also to construct the text (Holmes 2003, personal communication). Such is the case internationally 
where business schools routinely expect students to participate in group work projects. This course therefore sought to provide students with the experience of co-constructing text.

The observations reported below are generated from the prompts about coconstruction and are organised according to the particular aspect of activity theory they elucidate, including affordances, roles, rules, and mediating artefacts.

\section{The recognition of affordances in group work}

For many of the students in the course, group work itself was a new requirement, but one that was received with enthusiasm, despite the fact that they had had no part in negotiating the composition of the groups. The following two students demonstrate very positive feelings after an initial meeting with members of their group.

This group work system is superb. JSC 2

I am very satisfied with my group. All of them are very nice. LF 2

Students initially perceived a number of particular affordances through the group work. Some identified these affordances as language based, while others recognised that affordances lay in the ideas that would be shared by participants of a group.

8 or 9 working together that can improve my studying skill and speaking or something else. CGD 1

There are eight people in my group so anyone can give me some advice and suggestion after that I can collect some good idea to write the task which I have. CGD 2

In my group, many members come from different countries. We have our own ideas based on our own cultural background. Teamwork can make us exchange our ideas and get more information. LF 1

These perceptions endured for a number of participants, even though they clearly acknowledged some difficulties in achieving the object of the activity, which was at this later point to co-construct a full text, a more challenging activity than the previous.

\footnotetext{
Although it's difficult to work in group, group work can help us to see the other's opinions in the same thing for a person's ideas are always limited. LF7

Even I (We) will not get a good grade, We will be happy because we got valuable benefits or learnt from e.g. how to communicate, persuade and edit to each others' opinions or working. JSC 3
} 
The identification of friendship as an affordance, as seen in the comments below, was interesting and somewhat unexpected in the context of an academic course. However, it was a reminder to the teacher and researchers that the activity system operated beyond the classroom.

I am very happy that I can make friends with other members in this group. SF2

I have met people from different countries, talked to each other and worked together... I think I am in a wonderful group.... So, my group is a mixcultural group. LFL 2

My group was great. I haven't met people like them. They love working together like they have known each other for years. FF 3

\section{The roles mediating between object and community}

Neither the teacher nor the researchers gave students explicit directions or models describing how to manage the co-construction process (following Mitchell, Posner, \& Baecker, 1995, for example). Rather, the teacher expected the students to negotiate the manner in which the co-construction activity would proceed, using both physical (e.g. computer) and cognitive (e.g. language) tools. In many cases, students' initial expectations about how they would work together were positive, but not particularly strategically focussed, as the following statements show. Nor did students declare a need to specify a procedure.

I am sure that our first assignment will be done successfully...I think teamwork is the best way to do this task so far. LF 2

We will meet soon to talk about the assignment, and we will do the first task successfully. I am sure of it. KHC 2

When the groups were required to begin the co-construction of text, some students evaluated each member's role and contribution in a positive way.

All the members work very hard and provide many useful opinions for group report. SF 3

Some of us did a good job before discussion. All of us wanted to improve the task constantly and we spent a lot of time even on a word. LF 3

A number of other students however at this time acknowledged difficulty, stating that working in groups had not met their expectations. AE explains the change in her perceptions of the task in her third diary entry.

Before we started working together, I thought it could be easy that we work as a group, but now I have found it is very hard. AE3 
Others continued to support the activity, its purpose, and context, in the face of difficulty, and with a lack of confidence in the group's ability to achieve the outcome or object.

Anyway, we will try our best to reach agreement on the task.... I still think that teamwork is the best way for this kind of task, although it is not easy to do it. LF 3

Anyway, we can finish the group work. I have no idea what the point we will get. No matter how the result is good or bad, we can finish it... just I hope that group work will go better. We have some problems now, but it can be all right. KHC 3

Many of the problems with group work seemed to arise from the fact that the students did not appear to have means by which they could establish a successful working relationship, such as strategies for dealing with emerging problems and conflict, a shared understanding of procedure, and the assignment of roles in the co-construction of text.

The only area cause me concern is how to discuss this essay together with my group members. Do we have to write our own assignment first, then discuss about it or just write the group essay together? I need to find the best way of writing a group essay. LFL 7

Mitchell, Posner and Baecker (1995) usefully document three different strategies or stances that the students in their study used to carry out the task of collaborative writing. One such stance was scribe/consultant writing, where a scribe enters text in a document, and one or more consultants provide ideas but do not actually enter them in the document. The second involved parallel writing, in which writers individually enter text at the same time in the same document, but in different regions. The third stance was as joint writers where writers worked closely on one section of a document. AE, in her third diary entry, expresses her frustration with the joint writing process her group initially adopted. She clearly expresses her preference for the less demanding scribe/consultant process.

Because it was first time, and we did not have any experience before, so we did not ask that everyone took a part of the group work. It means we work all together and it was our mistake this time. I think for next one it could be better if we do each part with one or two members of the group and in the end when we put it all together there will not be any confusion.... Now I think working on an assignment personally is easier, because some of the students are confused still. They have done their work but in the meetings that we had they wanted to write it in group again instead of choosing the best part of each others writing and it makes work very hard. AE 3 
Another process, just as unsatisfactory for one student, was that of each student contributing a section of text, and all group members choosing the best section. One particular group bypassed computer interaction and met face to face in order to carry out this approach.

\begin{abstract}
After the first meeting we decided that everyone must done his or her individual research and report first. Then we met together again holding a discussing meeting. During that meeting, everyone showed individual work and we talked about that through sentence to sentence. Firstly, we chose the best one from all individual works for the group-project draft sentence. Then we discussed that and changed it into the best style.... Actually, it's a hard and stupid method when I thought about it again. It wasted us lots of time and we cannot get the same opinion. Because it's the first time we done things like that, we need time to get used to it and find the way just suit for us. LFL 3
\end{abstract}

\title{
Rules mediating subject and community
}

Many students had concerns about the difficulties their group faced in trying to achieve consensus necessary for the construction of a group text. Many students, as in the case below, talked of the difficulty of working with different group members' opinions and beliefs.

Well each person has done his or her individual work but when we met together, the problem appeared. Everyone has his or her own opinion. It's too hard to persuade other people to believe you. So, we have to spend a long time to get the only one answer, which sometimes you don't exactly agree. LFL 3

LFL articulated what other students may have felt, that English as the mediating language (an internal artefact or tool) is one source of difficulty. In addition, the diverse opinions and beliefs that the students brought to the tasks could also be considered internal or cognitive artefacts.

It is too hard to find exactly the same idea or to persuade other people to believe you especially English is not my own language. LFL 7

Prompts about the change in group size in the sixth diary entry resulted in largely positive comments indicating the belief that this would solve a number of problems associated with group work, particularly that of attempting to get the necessary consensus for jointly constructed text.

Fewer people will have fewer versions of the assignment. It will be easier to solve the arguments and achieve agreement. Also, it's much easier to hold a meeting together with fewer people. Furthermore, small group requires members more active on the work and prevents some group members from contributing nothing but count on their group mates. LF 6 
Another major problem, which arose in the co-construction process, was the variable commitment to the group work.

We can say, we did the work successfully if all people work hard to finish it, all of them come to meetings and when coming have finished their writing. AE 3

Some members of our group were arguing to choose sentences for the writing, and the others do not want to argue about it. So they were just watching it and do not care about it. I think it depends on group member who is difficult to discuss. KHC 3

Some students, observing variable commitment on the part of different group members, believed this would change over time, expressed tolerance and indifference or, as in CGD's case, had a simple strategy to exclude a non participating group member.

In my opinion, the first assignment of group that is a big challenge for every groups, because we haven't get agreement with others, but I believe we will know others well after the first task! SF 2

One or two guys do not care about the assignment so we do not exist their name on the sheet of cover. CGD 5

KHC also identified the lack of a shared commitment to and understanding of the activity. His response was so strong that he actively tried to renegotiate the way the group carried out the writing.

In fact, I want to be out of my group. I know that it is more helpful for me to improve my writing. However, I cannot adapt doing this in my group....It depends on people who are eager to study or not. Group work can be the one, which gives some help for improving writing skill. However, most important thing is the attitude of mind for study. KHC 4

\section{Reflections on the co-construction process: Roles and rules}

In later diary entries, the researchers provided students with prompts to reflect on the process of co-construction. One such prompt asked for suggestions on how the group could function more effectively. The strategy advocated by these members, related to roles and rules, was to share out activities or sections of text to write.

I think it will be easier if the group divided themselves up and then give each group different questions to work and concentrate on. And after they finished working on them then they will get together and discuss and examine their work carefully. I think it will save them time. FF 3

Our group has eight people. So I think we could divide it into 4 small groups. Each group concentrates on one question and takes responsibility 
for that. Then we just need hold one meeting to check grammar, spelling and main idea. That will be easy to get the best answer....The less people the better to discuss and get one answer. LFL 3

\section{The computer as mediating artefact or tool}

It was clear in the first diary entries that many students lacked experience with computers and were unfamiliar with computer mediated instruction. However, while some students articulated challenges and constraints, which centred on access to computers and the Internet, they quickly recognised the convenience of Class Forum and particularly noticed the affordance of quick and easy access to information both about and for the course.

The expectation for the activity of co-construction was that students would use Class Forum or face to face meetings for their interactions, since the teacher did not set aside time in class for students to get together. The lecturer articulated the need for group meetings, but it was not formally organised by her, as mentioned above. SF, in his third diary entry reported effective functioning of his group, enabled by the use of the computer.

We use internet to send our messages and materials to other people; we can share them and make them as beneficial means. SF 3

No other groups reported using Class Forum at all as a mediator for the activity.

\section{An alternative activity system?}

Some students expressed a preference for returning to a more familiar way of constructing text - alone. Students who preferred isolated writing described an activity system with different goals from those the researchers intended and without co-construction of text. LFL expresses this view clearly.

I think it will be easy to write the essay by myself. I could find the information which I think is the best or useful and I do not have to worry about other people's feeling or thinking. I just need write the essay under my idea and do not have to think about other people's opinion. No discussion, no group meeting that will be so nice for me. LFL 7

However, the researchers and teacher are committed to retaining the activity of co-construction for the reasons stated in the beginning of the observations section. In evaluating students' responses to the activity of coconstruction, the researchers and teacher of the course reflected on the questions posed by Jonassen and Rohrer-Murphy (1999) in Appendix 1, 
which pertain to the mediators and the context in which the activity took place. Answers to these questions in particular provided insight into the way in which we could interpret the activity system, particularly with respect to the process of the group interaction.

It was clear that some groups operated in a cohesive way (as defined by Tyson 1998), where members liked each other, appreciated the contributions of other members, and agreed on the goals and outcomes and the way in which the members could accomplish them. However, what was brought to the teacher's and researchers' attention was the difficulty many had in managing the group process, and the interpersonal conflict that resulted. On a number of occasions, students communicated with the teacher about conflict with other group members because of differences in opinions and ideas. Particularly with co-construction of text, they sometimes conveyed difficulty in reaching agreement and that they had arrived at an impasse. "Moments of impasse call for particular skills and strategies if the group is to benefit from the opportunity each such incident offers for learning..." (Tyson, 1998, p. 119).

While not in a position to immediately react to this lack of guidance, the teacher of the course is in a position to put into place procedures to guide students through the process of co-construction of text in subsequent courses.

Tyson (1998) identifies both interpersonal conflicts as discussed above, and also internal conflict occurring at a personal level. As seen in the data above, students expressed ambivalence and internal conflict on a number of levels. They felt enthusiasm but concern; they felt positive about the group members but could see no way in which the outcome could be achieved; they felt good about the grade achieved but could still not feel positive about the group process. With respect particularly to peer evaluation conducted by the groups, there appeared to be conflict between the need to achieve this for course credit and the possibility of offending other course members. Carson and Nelson (1994) state (in regard to Chinese students) that "the impetus/motivation behind their responses is likely to come from a need for a positive group climate rather than a need to help an individual writer" (1994, p. 23). Responses to the work of others may therefore be 'compromised' by the need to maintain group harmony.

The framework provided by activity theory allowed us to appreciate that different students' perceptions about and ways of carrying out activities were very different, that their perceptions can be volatile and subject to change, that some students readily adopt and share a teacher's purposes and enthusiasm for activities, while others continue to contest those. 


\section{Conclusion}

The data generated using regular, focused and private communication with the teacher by means of Class Forum was extremely rich and informative. The journal entries were an affordance to us as researchers. They allowed us a view of the students' approaches to and issues with activities prescribed by the teacher.

An activity theoretic analysis is capable of generating insights otherwise lost in more conventional ways of conducting research in language classrooms. Furthermore, activity theory employs an analytic framework that allows for interpretations that emerge from the practices of the participants rather than for those that the framework imposes. In researching and attempting to apply an activity theory orientation, we became aware of the fact that activity theory is a type of lens, a lens that generates a perspective that is particular to the context, but an approach which can be generalised to other research contexts. Prior (1998) makes the point that while "we can never step in the same stream of activity twice, ... a functional system can be typified (i.e. relatively stabilised or prefabricated)" (p. 186).

\section{References}

Belz, J. A. (2002). Social dimensions of telecollaborative foreign language study. Language Learning \& Technology, 6(1), 60-81. [viewed 10 Oct 2005, verified $27 \mathrm{Feb}$ 2006] http:/ /llt.msu.edu/vol6num1/belz/

Blin, F. (2004). CALL and the development of learner autonomy: Towards an activity-theoretical perspective. Recall, 16(2), 377-395.

Brine, J. W., Johnson, E. M., Franken, M. \& Campbell, L. (2002). Collaborative second language writing: An activity analysis of web conferencing. In L. R. Kinshuk, K. Akahori, R. Kemp, T. Okamoto, L. Henderson, \& C. H. Lee (Eds), Proceedings of the International Conference on Computers in Education (pp.668-669). Los Alamitos, CA: IEEE Computer Society. [verified 28 Feb 2006] http://csdl2.computer.org/comp/proceedings/icce/2002/1509/00/15090668.pdf

Carson, J. \& Nelson, G. (1994). Writing groups: Cross-cultural issues. Journal of Second Language Writing, 3, 17-30.

Cole, M. \& Engestrom, Y. (1993). A cultural approach to distributed cognition. In G. Salomon (Ed), Distributed cognitions: Psychological and educational considerations (pp. 1-46). New York: Cambridge University Press.

Engestrom, Y. (1991). Activity theory and individual and social transformation. Activity Theory, 7(8), 6-17.

Ferris, D. and Hedgcock, J.S. (1998). Teaching ESL composition: Purpose, process and practice. Mahwah, NJ: Lawrence Erlbaum Associates. 
Franken, M. (1997). The effect of talk in argument text construction. Unpublished PhD thesis, Victoria University of Wellington.

Franken, M. \& Haslett, S. (2002). When and why talking can make writing harder. In S. Ransdell \& M.L. Barbier (Eds), New directions for research in L2 writing. Volume 11 (pp. 208-229). Amsterdam: Kluwer.

Gibson, J. J. (1979). The ecological approach to visual perception. Boston: Houghton Mifflin.

Hutchby, I. (2001). Technologies, texts and affordances. Sociology, 35, 441-456.

Jonassen, D.H. \& Rohrer-Murphy, L. (1999). Activity theory as a framework for designing constructivist learning environments. Educational Technology Research and Development, 47, 61-79.

Kaptelinin, V, Nardi, B. \& MacCauley, C. (1999). The activity checklist: A tool for representing the "space" of context. Interactions, July and August, 27-39.

Lantolf, J.P. (Ed) (2000). Sociocultural theory and second language learning: Recent advances. Oxford University Press.

Leont'ev, A. N. (1981). The problem of activity in psychology. In J. Wertsch (Ed), The concept pf activity in Soviet psychology (pp. 37-71). Armonk, NY: M.E. Sharpe.

Lewis, R. (1997). An activity theory framework to explore distributed communities. Journal of Computer Assisted Learning, 13, 210-218.

Lincoln, Y. S. \& Guba, E. G. (1985). Naturalistic inquiry. Newbury Park, CA: Sage Publications.

Mitchell, A., Posner, I. \& Baecker, R. (1995). Learning to write together using Groupware. CHI'95 Proceedings. [viewed 6 Jul 2002, verified 27 Feb 2006] http://www.acm.org/sigchi/chi95/Electronic/documnts/papers/am_bdy.htm

Prior, P. (1998). Writing/disciplinarity: A sociohistoric account of literate activity in the academy. Mahwah, NJ: Lawrence Erlbaum.

Russell, D. R. (1997). Rethinking genre in school and society: An activity theory analysis. Written Communication, 14, 504-554

Smagorinsky, P. (1997). Personal growth in social context. A high school senior's search for meaning in and through writing. Written Communication, 14, 63-105.

Thorne, S. L. \& Payne, J. S. (2005). Evolutionary trajectories, Internet-mediated expression, and language education. CALICO Journal, 22(3), 371-397.

Tyson, T. (1998). Working with groups (2nd edition). South Yarra: Macmillan Education.

Van Lier, L. (2000). From input to affordance: Social-interactive learning from an ecological perspective. In J.P. Lantolf (Ed), Sociocultural theory and second language learning: Recent advances (pp.245-259). Oxford University Press.

Watson-Gegeo, K. A. (2004). Mind, language, and epistemology: Toward a language-socialization paradigm for SLA. Modern Language Journal, 88(3), 331350 . 


\section{Appendix 1: Questions guiding the application of an activity theory orientation}

(adapted from Jonassen \& Rohrer-Murphy, 1999)

\begin{tabular}{|c|c|}
\hline AT feature & Guiding question \\
\hline $\begin{array}{l}\text { purpose of } \\
\text { the activity } \\
\text { system }\end{array}$ & $\begin{array}{l}\text { What general problems do students have to deal with? } \\
\text { Where and when do these problems arise? } \\
\text { What are the communications that surround the activity? } \\
\text { What expectations are there of the students? } \\
\text { Whose expectations are these? } \\
\text { What are the goals/motives of the students? }\end{array}$ \\
\hline $\begin{array}{l}\text { activity } \\
\text { system } \\
\text { (subject/ } \\
\text { object/ } \\
\text { community/ } \\
\text { rules/ } \\
\text { division of } \\
\text { labour) }\end{array}$ & $\begin{array}{l}\text { Who are the participants? } \\
\text { What are their beliefs? } \\
\text { What is the expected outcome of the activity? } \\
\text { What criteria will be used to evaluate the outcome? } \\
\text { What are the implied roles for the participants? } \\
\text { What are the goals / motives of the activity and how do they relate to } \\
\text { those of others and society } \\
\text { How formally are the rules of interaction stated? } \\
\text { What is the structure of social interactions surrounding the activity? } \\
\text { Are there contradictions/inconsistencies within the needs of the } \\
\text { participants and the goals of the learning activities? }\end{array}$ \\
\hline $\begin{array}{l}\text { activity } \\
\text { structure }\end{array}$ & $\begin{array}{l}\text { How is the work being done in practice? } \\
\text { What are the activities in which participants participate } \\
\text { How has the work (actions and operations) been transformed over } \\
\text { time? } \\
\text { What norms, rules and procedures in the actions and operations } \\
\text { have been documented? }\end{array}$ \\
\hline mediators & $\begin{array}{l}\text { What are the physical (instruments, machines) and/or cognitive } \\
\text { (signs, procedures, methods, languages, etc) tools used to perform } \\
\text { this activity? } \\
\text { How readily available are they to participants? } \\
\text { What formal or informal rules, assumptions or standardised } \\
\text { methods guide the activity? } \\
\text { How might these rules have evolved? } \\
\text { How widely understood are they? } \\
\text { Who traditionally has assumed the various roles? } \\
\text { How do these roles relate to the individual's non-academic } \\
\text { experiences? } \\
\text { Can individuals get others to take on new or different roles? } \\
\text { What forces drive the role changes? }\end{array}$ \\
\hline the context & $\begin{array}{l}\text { What beliefs or assumptions are commonly held by the group? } \\
\text { What tools did they find (un)helpful in completing projects? } \\
\text { How much freedom do individuals have about entering a } \\
\text { workgroup? } \\
\text { What is the structure of social interactions surrounding the activity? } \\
\text { How are tasks organised, shared, or divided amongst the } \\
\text { participants? } \\
\text { How will these roles and their contribution be evaluated? }\end{array}$ \\
\hline
\end{tabular}




\section{Appendix 2: Diary entry prompts and Task requirements}

\begin{tabular}{|c|c|c|}
\hline Entry Number & Question prompt & Group task \\
\hline $\begin{array}{l}\text { Entry } 1 \\
\text { purpose and } \\
\text { expectations }\end{array}$ & $\begin{array}{l}\text { How do you feel about the course as a } \\
\text { whole? } \\
\text { How do you feel about particular aspects of } \\
\text { the course the teacher has introduced to you } \\
\text { eg. assessment guidelines, working in } \\
\text { groups, using the computer as a way of } \\
\text { getting information for your writing? } \\
\text { How does this course compare with } \\
\text { previous experiences of learning academic } \\
\text { writing? }\end{array}$ & $\begin{array}{l}\text { Each } 10 \text { student } \\
\text { group required to: } \\
\text { - carry out library } \\
\text { research on a } \\
\text { topic set by the } \\
\text { tutor. } \\
\text { - submit a report } \\
\text { plus an annotated } \\
\text { bibliography of } 3 \\
\text { items. }\end{array}$ \\
\hline \begin{tabular}{|l|} 
Entry 2 \\
purpose and \\
expectations
\end{tabular} & $\begin{array}{l}\text { How do you feel about the group you have } \\
\text { been put into? } \\
\text { Do you think the group can achieve the first } \\
\text { task successfully? } \\
\text { Have you got other ideas about how this } \\
\text { task could be done? }\end{array}$ & $\begin{array}{l}\text { - read and } \\
\text { comment on } \\
\text { others' reports. } \\
\text { - co-construct an } \\
\text { introduction. } \\
\text { - read and } \\
\text { comment on other } \\
\text { groups' } \\
\text { introductions }\end{array}$ \\
\hline \begin{tabular}{|l|} 
Entry 3 \\
activity \\
structure: roles \\
and rules
\end{tabular} & $\begin{array}{l}\text { Have your feelings about your group and } \\
\text { the group task changed in any way? } \\
\text { How does the group work out what each } \\
\text { person will do? } \\
\text { Does the group do this successfully? } \\
\text { Have you got other ideas about how this } \\
\text { could be done? }\end{array}$ & \multirow{5}{*}{$\begin{array}{l}\text { Each } 4-5 \text { student } \\
\text { group required to: } \\
\text { - carry out library } \\
\text { research on a } \\
\text { topic set by the } \\
\text { tutor. } \\
\text { - submit a report } \\
\text { with introduction, } \\
\text { plus a 3-item } \\
\text { annotated } \\
\text { bibliography. } \\
\text { - co-construct a full } \\
\text { comparison and } \\
\text { contrast } \\
\text { assignment. } \\
\text { read and } \\
\text { comment on other } \\
\text { groups' } \\
\text { assignments. } \\
\text { post assignments } \\
\text { and responses to } \\
\text { the class } \\
\text { discussion list. } \\
\text { - use email to } \\
\text { coordinate shared } \\
\text { work. }\end{array}$} \\
\hline \begin{tabular}{|l|} 
Entry 6 \\
activity system
\end{tabular} & $\begin{array}{l}\text { How do you feel about your new group? } \\
\text { Is it easier to work with a group this size? }\end{array}$ & \\
\hline \begin{tabular}{|l} 
Entry 7 \\
activity \\
structure
\end{tabular} & $\begin{array}{l}\text { How are you finding the task of } \\
\text { commenting on other peoples' work? } \\
\text { How do you feel about the group essay? } \\
\text { Are there any areas which cause you } \\
\text { concern? } \\
\text { How different would it be if you were } \\
\text { writing the essay on your own? }\end{array}$ & \\
\hline \begin{tabular}{|l|} 
Entry 8 \\
purpose, \\
activity system \\
and structure
\end{tabular} & $\begin{array}{l}\text { How do you feel about the finished } \\
\text { assignment? } \\
\text { Are you satisfied with it? } \\
\text { Does it meet your expectations? } \\
\text { How do you think the group worked? }\end{array}$ & \\
\hline \begin{tabular}{|l|} 
Entry 10 \\
purpose, object, \\
transformations \\
over time
\end{tabular} & $\begin{array}{l}\text { How do you feel about your ability to write } \\
\text { an essay on your own? } \\
\text { Has the group writing influenced how you } \\
\text { feel in any way? } \\
\text { Do you think the group way of assessing } \\
\text { your writing worked well? }\end{array}$ & \\
\hline
\end{tabular}


John Brine teaches in the Center for Language Research at the University of Aizu, Japan, and is a member the Graduate School for Information Systems. His research interests are in the sociocultural aspects of computer assisted language learning.

John Brine, Center for Language Education, The University of Aizu Tsuruga, Ikkimachi, Aizu-Wakamatsu, Fukushima, Japan. Email: brine@u-aizu.ac.jp

Margaret Franken teaches in the postgraduate program in Language and Literacy Education at the University of Waikato, New Zealand. She has published in the area of second language writing and academic literacy. She is a former editor of the TESOLANZ Journal, and of New Zealand Studies in Applied Linguistics.

Dr Margaret Franken, Arts and Language Education, School of

Education, The University of Waikato, Private Bag 3105, Hamilton, New

Zealand. Email: franken@waikato.ac.nz 